\title{
Synergistic Regulation of Immunoreceptor Signaling by SLP-76-Related Adaptor Clnk and Serine/Threonine Protein Kinase HPK-1
}

\author{
JIE YU, ${ }^{1}$ CATHERINE RIOU ${ }^{1}$ DOMINIQUE DAVIDSON,${ }^{1}$ RAMAN MINHAS, ${ }^{1,2}$ JEFFREY D. ROBSON, ${ }^{1,2}$ \\ MICHAEL JULIUS, ${ }^{3,4}$ RUEDIGER ARNOLD,${ }^{5}$ FRIEDEMANN KIEFER, ${ }^{5}$ AND ANDRÉ VEILLETTE ${ }^{1,2,6,7 *}$ \\ Laboratory of Molecular Oncology, IRCM, Montréal, Québec, Canada H2W 1R7 ${ }^{1}$; Departments of Biochemistry, ${ }^{2}$ \\ Medicine, ${ }^{6}$ and Microbiology and Immunology, ${ }^{7}$ McGill University, Montréal, Québec, Canada H3G 1Y6; \\ Sunnybrook and Women's College Health Sciences Centre ${ }^{3}$ and the Departments of Immunology and Medical \\ Biophysics, ${ }^{4}$ University of Toronto, Toronto, Ontario, Canada M4N 3M5; and the Max-Planck-Institute for \\ Physiological and Clinical Research, W. G. Kerckhoff-Institute, D-61231 Bad Nauheim, Germany ${ }^{5}$
}

Received 20 March 2001/Returned for modification 26 April 2001/Accepted 18 June 2001

\begin{abstract}
Recently, the identification of CInk, a third member of the SLP-76 family of adaptors expressed exclusively in cytokine-stimulated hemopoietic cells, has been reported by us and by others. Like SLP-76 and BInk, Clnk was shown to act as a positive regulator of immunoreceptor signaling. Interestingly, however, it did not detectably associate with known binding partners of SLP-76, including Vav, Nck, and GADS. In contrast, it became complexed in activated $T$ cells and myeloid cells with an as yet unknown tyrosine-phosphorylated polypeptide of $\sim 92 \mathrm{kDa}$ (p92). In order to understand better the function of Clnk, we sought to identify the Clnk-associated p92. Using a yeast two-hybrid screen and cotransfection experiments with Cos-1 cells, evidence was adduced that p92 is HPK-1, a serine/threonine-specific protein kinase expressed in hemopoietic cells. Further studies showed that Clnk and HPK-1 were also associated in hemopoietic cells and that their interaction was augmented by immunoreceptor stimulation. A much weaker association was detected between HPK-1 and SLP-76. Transient transfections in Jurkat $T$ cells revealed that Clnk and HPK-1 cooperated to increase immunoreceptor-mediated activation of the interleukin 2 (IL-2) promoter. Moreover, the ability of Clnk to stimulate IL-2 promoter activity could be blocked by expression of a kinase-defective version of HPK-1. Lastly we found that in spite of the differential ability of Clnk and SLP-76 to bind cellular proteins, CInk was apt at rescuing immunoreceptor signaling in a Jurkat T-cell variant lacking SLP-76. Taken together, these results show that Clnk physically and functionally interacts with HPK-1 in hemopoietic cells. Moreover, they suggest that CInk is capable of functionally substituting for SLP-76 in immunoreceptor signaling, albeit by using a distinct set of intracellular effectors.
\end{abstract}

The activation of immune cells via antigen receptors or receptors for the Fc portion of immunoglobulins (so-called immunoreceptors) is a critical element of the normal immune response $(37,42)$. Previous studies have shown that immunoreceptor signaling is initiated by ligand-induced tyrosine phosphorylation of a short sequence present in these receptors, named the immunoreceptor tyrosine-based activation motif. This motif functions by orchestrating the recruitment and activation of members of the Src, Syk/Zap-70, and Btk families of cytoplasmic protein tyrosine kinases (PTKs) (4, 33). These various PTKs mediate the tyrosine phosphorylation of several cellular polypeptides in response to immunoreceptor stimulation, including adaptors, such as LAT and SLP-76-related molecules, and enzymatic effectors, such as phospholipase $\mathrm{C}$ gamma (PLC- $\gamma$ ) and the exchange factor $\operatorname{Vav}(5,36,41)$. In turn, these events trigger intracellular calcium fluxes, the Rasmitogen-activated protein kinase (MAPK) cascade, lipid metabolism, and cytoskeletal reorganization, thereby leading to activation of such transcription factors as NFAT and AP-1. Ultimately, immunoreceptor signaling culminates in the induc-

* Corresponding author. Mailing address: Laboratory of Molecular Oncology, IRCM, 110 Pine Ave. West, Montréal, Québec, Canada H2W 1R7. Phone: (514) 987-5561. Fax: (514) 987-5562. E-mail: veillea @ircm.qc.ca. tion of effector functions, including the production of interleukin 2 (IL-2) or gamma interferon (IFN- $\gamma$ ), cytolysis, and degranulation.

The SLP-76 family of adaptors comprises three members, named SLP-76, Blnk, and Clnk (3, 12-14, 20, 43). These molecules possess a related primary structure, including, from the amino terminus to the carboxy terminus, the following: (i) a basic region; (ii) an acidic domain with sites of tyrosine phosphorylation and proline-rich regions known or presumed to be involved in interactions with $\mathrm{SH} 2$ and $\mathrm{SH} 3$ domain-containing effectors; (iii) an SH2 domain; and (iv) a short carboxy-terminal extension of undetermined function. Whereas SLP-76 is widely expressed in T cells, natural killer (NK) cells, platelets, myeloid cells, and mast cells (6), the Blnk protein is contained mostly in B cells $(12,13,43)$. By opposition, Clnk appears to accumulate exclusively in cytokine-stimulated hemopoietic cells $(3,14)$. These include IL-2-induced T cells and NK cells and IL-3-propagated mast cells and myeloid cells. Earlier studies demonstrated that SLP-76 physically interacts with signaling molecules, such as the exchange factor Vav and the adaptors Nck, GADS, and Fyb/SLAP-130 (5, 36, 38). In a similar way, Blnk associates with Vav, phospholipase C gamma (PLC$\gamma$ ), Nck, and Grb2. As a result of these associations, SLP-76 and Blnk play critical roles in immunoreceptor-induced calcium fluxes and Ras-MAPK activation, and they are required 
for the induction of effector functions. They are also essential for T-cell and B-cell development, respectively (7, 16, 22, 30, 34).

There is considerably less information available regarding the role of Clnk in immune cell signaling and activation. We previously noted that unlike its relatives, Clnk does not detectably associate with Vav, GADS, or Nck (3) (our unpublished results). However, Clnk becomes complexed with an unidentified 92-kDa tyrosine-phosphorylated protein (p92) upon antigen receptor-induced activation of $\mathrm{T}$ cells or Fc $\gamma \mathrm{RI}$-mediated stimulation of myeloid cells. It was also observed that overexpression of Clnk in Jurkat $\mathrm{T}$ cells caused a pronounced increase in antigen receptor-triggered activation of NFAT, AP-1, and IL-2 promoter activity (3). Likewise, others reported that enforced expression of Clnk in the rat basophil leukemia cell line RBL-2H3 augmented FceRI-triggered degranulation (14). Hence, similar to its relatives, Clnk is likely to be involved in the positive regulation of immunoreceptor signaling.

In this report, we have attempted to understand better the role of Clnk in immunoreceptor-mediated signal transduction by identifying the Clnk-associated p92. The results of our studies show that p92 is likely to be HPK-1, a serine/threoninespecific protein kinase expressed in hemopoietic cells. Moreover, they indicate that Clnk cooperates with HPK-1 in order to regulate positively immunoreceptor-mediated signaling events.

\section{MATERIALS AND METHODS}

Cells. 5.32.5 (clone 2.5) is an IL-2-dependent CD4-positive antigen-specific T-cell clone, and it was propagated in IL-2-containing medium as described elsewhere (15). The IL-3-dependent mouse myeloid cell line B6Sut $\mathrm{A}_{1}$ was grown in RPMI 1640 supplemented with $10 \%$ fetal bovine serum (FBS), glutamine, and antibiotics, as well as 5\% WEHI-3B supernatant (as a source of IL-3). Cos-1 cells were propagated in $\alpha$ minimal essential medium containing $10 \%$ FBS, glutamine, and antibiotics. Parental Jurkat T-cells (clone E6.1), Jurkat Tag, and a SLP-76deficient variant of Jurkat (J14) (kindly provided by Art Weiss, University of California in San Francisco) (44) were grown in RPMI 1640 medium supplemented with $10 \%$ FBS, glutamine, and antibiotics.

Antibodies. Affinity-purified anti-Clnk antibodies were described elsewhere (3). Polyclonal antibodies directed against mouse SLP-76 were produced by immunizing rabbits with a bacterial fusion protein encompassing amino acids 158 to 235 of the mouse SLP-76 protein (20). Both anti-Clnk and anti-SLP-76 antibodies react with sequences positioned outside their SH2 domain. AntiHPK-1 antibodies were also generated in rabbits, using fusion proteins containing either amino acids 451 to 491 (serum \#208) or amino acids 321 to 360 (serum \#211) of the mouse HPK-1 sequence (23). Polyclonal rabbit anti-Lck antibodies were described previously (1). Anti-FLAG monoclonal antibody (MAb) M2 and antiphosphotyrosine MAb 4G10 were purchased from Sigma (Oakville, Ontario, Canada) and Upstate Biotechnology (Lake Placid, N.Y.), respectively. Antihemagglutinin (anti-HA) MAb 12CA5 was described elsewhere (2).

cDNAs and constructs. Mouse cDNAs encoding Clnk, wild-type HPK-1, kinase-defective HPK-1 (lysine 46 to glutamate 46 [K46E] mutant), HA-tagged HPK-1, and Lck were described elsewhere $(3,23)$. A mouse slp-76 cDNA was kindly provided by Gary Koretzky (University of Pennsylvania, Philadelphia) (20). Constructs encoding glutathione $S$-transferase (GST) fusion proteins encompassing the SH2 domain of Clnk (either wild-type or arginine 335 to lysine 335 mutant) or SLP-76 were produced by PCR. cDNAs producing versions of Clnk and SLP-76 bearing a FLAG epitope at the amino terminus were also generated by PCR. All constructs were verified by sequencing to ensure that no unwanted mutation was introduced in the process of their creation (data not shown). For expression in Cos-1 cells and Jurkat $\mathrm{T}$ cells, cDNAs were cloned either in pXM139 (for Clnk, SLP-76, and Lck) or in pMT2 (for HPK-1).

Cell stimulation. Clone 2.5 was activated via the T-cell antigen receptor (TCR) by stimulation for $3 \mathrm{~min}$ at $37^{\circ} \mathrm{C}$ in the presence of anti-CD3 $\mathrm{MAb}$ 145-2C11 and rabbit anti-hamster immunoglobulin $\mathrm{G}(\operatorname{IgG})$. B6Sut $\mathrm{A}_{1}$ was activated via Fc $\gamma \mathrm{RI}$ by incubation for $3 \mathrm{~min}$ at $37^{\circ} \mathrm{C}$ with mouse $\operatorname{IgG}_{2 \mathrm{a}}$ followed by
$\mathrm{F}\left(\mathrm{ab}^{\prime}\right)_{2}$ fragments of sheep anti-mouse IgG. After stimulation, cells were lysed in TNE buffer ( $1 \times$ TNE is $50 \mathrm{mM}$ Tris [pH 8.0], $1 \%$ Nonidet P-40, 2 mM EDTA) supplemented with protease and phosphatase inhibitors as detailed elsewhere (10).

Immunoprecipitations and immunoblots. For immunoprecipitation, postnuclear lysates were incubated with the appropriate antibodies for $2 \mathrm{~h}$. Immune complexes were then recovered with formalin-fixed Staphylococcus aureus (Pansorbin; Calbiochem-Novabiochem, San Diego, Calif.). After three washes, proteins were eluted in sample buffer and resolved by sodium dodecyl sulfatepolyacrylamide gel electrophoresis. For reimmunoprecipitation experiments, immunoprecipitates were eluted in sample buffer lacking $\beta$-mercaptoethanol, boiled, and then diluted 1:10 with lysis buffer. Specific proteins were subsequently recovered by immunoprecipitation with the indicated antibodies. For analysis of Clnk and HPK-1 expression in transiently transfected Jurkat cells, cells were lysed directly in boiling sodium dodecyl sulfate-containing sample buffer, and lysates corresponding to equivalent cell numbers were resolved by gel electrophoresis. Immunoblots were done according to a previously described protocol (39), using either ${ }^{125}$ I-goat anti-mouse IgG (ICN Biomedicals, Aurora, Ohio) or ${ }^{125}$ I-protein A (Amersham Pharmacia Biotech, Baie d'Urfé, Québec, Canada).

In vitro binding assays. GST fusion proteins were produced in bacteria and purified on agarose-glutathione beads as described elsewhere (32). In vitro binding assays were performed using $\sim 0.5 \mu \mathrm{g}$ of GST fusion proteins and $3 \mathrm{mg}$ of lysates from resting or stimulated B6Sut $\mathrm{A}_{1}$ cells. After several washes, bound proteins were eluted in sample buffer and detected by immunoblotting with antiphosphotyrosine antibodies.

Immune-complex kinase assays. HPK-1 was transiently expressed in Cos-1 cells, in the absence or the presence of Clnk. Proteins were immunoprecipitated from postnuclear lysates with either anti-HPK-1 or anti-Clnk antibodies. After several washes, immune-complex kinase reactions were performed for $10 \mathrm{~min}$ at $30^{\circ} \mathrm{C}$ as described previously (23), in the presence of $20 \mathrm{mM}$ cold ATP, $10 \mu \mathrm{Ci}$ of $\left[\gamma^{-32} \mathrm{P}\right]$ ATP (New England Nuclear Life Science Products, Boston, Mass.), and histone H2A (5 $\mu \mathrm{g}$; Roche Diagnostics, Laval, Québec, Canada) as an exogenous substrate. Under these conditions, reactions were linear for at least $30 \mathrm{~min}$ (data not shown). For Jurkat $\mathrm{T}$ cells, cells were transfected with a cDNA coding for HA-tagged HPK-1, with or without FLAG-tagged Clnk. After 48 h, cells were stimulated or not with anti-CD3 MAb OKT3 and lysed, and HPK-1 was immunoprecipitated with anti-HA MAb 12CA5. HPK-1 kinase activity was measured in vitro as described elsewhere (26), using a fusion protein bearing the aminoterminal domain of c-Jun [GST-c-Jun(N)] as an exogenous substrate.

Yeast two-hybrid screen. Sequences corresponding to the SH2 domain of Clnk were inserted in the SalI site of the yeast expression vector pBTM116/Src (provided by M. Lioubin and L. Rohrschneider, Fred Hutchinson Cancer Center, Seattle, Wash.) (40). In addition to the DNA-binding domain of LexA, this vector contains the Src kinase (with tyrosine-to-phenylalanine mutations at positions 416 and 527), which allows tyrosine phosphorylation of potential targets in yeast cells. The construct was stably expressed in the yeast strain L40, according to standard protocols (8). After confirming adequate expression of ClnkSH2LexA ("bait") and Src (data not shown), yeast cells were transformed with a mouse thymocyte cDNA library cloned in the expression vector pHybriZAP (generated by Serge Lemay, McGill University, Montréal, Québec, Canada, and Stratagene, La Jolla, California) (27). This vector bears the transactivation region of Gal4. Transformants were selected for their ability to grow in medium lacking histidine and for the presence of $\beta$-galactosidase activity (data not shown). More than 100 independent clones were subsequently subjected to elimination of the bait, and those showing concomitant loss of $\beta$-galactosidase activity were kept for further analyses. Plasmids were rescued from these yeast cells according to standard protocols and analyzed by sequencing, restriction enzyme digestions, or both (data not shown). To determine whether binding to the Clnk SH2 domain in the yeast two-hybrid system required the presence of Src, L40 was transformed with pBTM116 alone, pBTM116-Clnk SH2, or pBTM116/Src-Clnk SH2. Individual colonies were then transformed with the various plasmids recovered in the two-hybrid screen. Stable transformants were tested for the ability to grow in medium lacking histidine and $\beta$-galactosidase activity.

Transient transfections. Cos- 1 cells were transiently transfected by the DEAE-dextran method, as described elsewhere (11). Jurkat cells were transfected by electroporation with the indicated plasmids (unless specified, $10 \mu \mathrm{g}$ ), in the presence of $20 \mu \mathrm{g}$ of either pNFAT-luciferase, pAP-1-luciferase, pIL-2 promoter-luciferase or $\mathrm{p} \gamma$-IFN promoter-luciferase, according to a protocol detailed elsewhere (3). After $40 \mathrm{~h}, 10^{6}$ viable cells were stimulated for $7 \mathrm{~h}$ in duplicate with anti-CD3 MAb OKT3 $(1 \mu \mathrm{g} / \mathrm{ml})$ alone or a combination of phorbol myristate acetate (PMA) $(100 \mathrm{ng} / \mathrm{ml})$ and ionomycin $(0.75 \mu \mathrm{g} / \mathrm{ml})$. Cells were then 


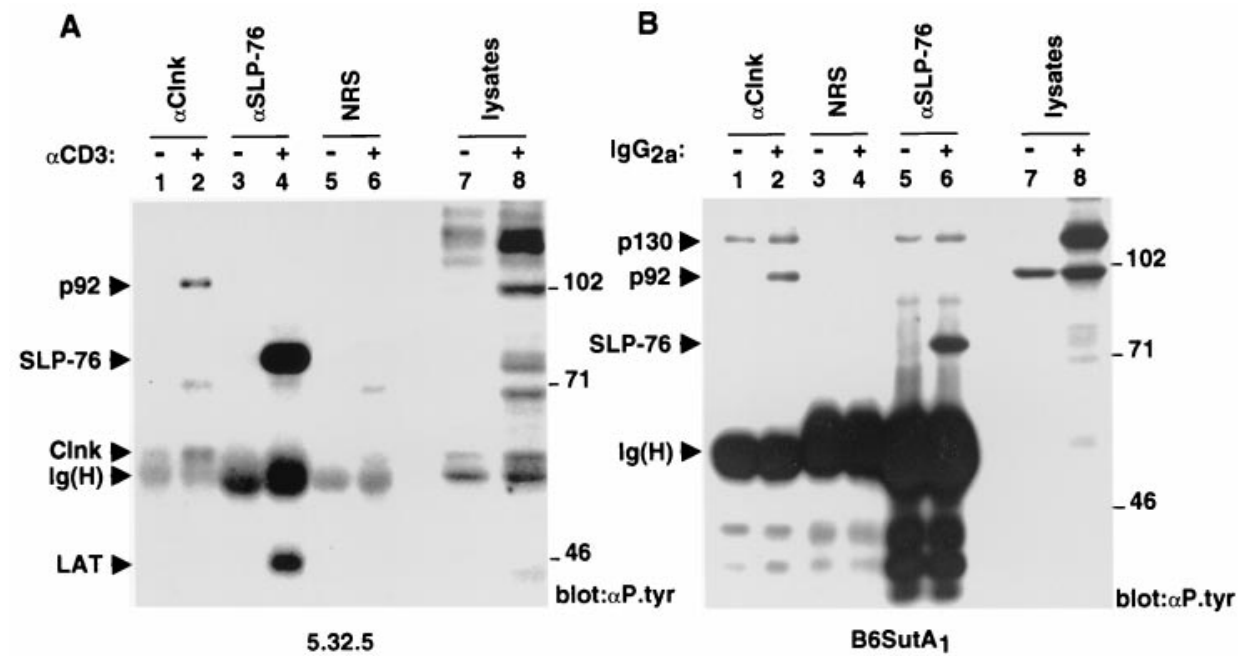

FIG. 1. Differential association of tyrosine-phosphorylated p92 with Clnk and SLP-76 in activated hemopoietic cells. Cells were activated as detailed in the text. After lysis, individual polypeptides were immunoprecipitated with the indicated antibodies (e.g., anti-Clnk $[\alpha C l n k])$, and the presence of associated phosphotyrosine-containing molecules was determined by immunoblotting with antiphosphotyrosine ( $\alpha$ P.tyr) antibodies. The migrations of prestained molecular mass markers are indicated on the right, while those of p130, p92, SLP-76, Clnk, LAT, and the heavy chain of $\operatorname{Ig}[\operatorname{Ig}(\mathrm{H})]$ are shown on the left. (A) IL-2-dependent antigen-specific T-cell line 2.5. The $\sim 70-\mathrm{kDa}$ tyrosine-phosphorylated product that was nonspecifically coimmunoprecipitated with the various antibodies in activated cells is likely to be Zap-70. Exposure, 16 h. (B) IL-3-dependent

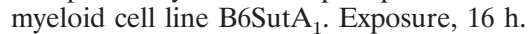

lysed and assayed for luciferase activity using the luciferase reporter assay system (Promega, Madison, Wis.) and a luminometer (EG\&G Berthold, Bad Wildbad, Germany). Results are presented as the percentage of luciferase activity induced by PMA plus ionomycin. Expression of the transfected constructs was monitored by immunoblotting of total cell lysates with the appropriate antibodies.

\section{RESULTS}

Differential association of CInk and SLP-76 with tyrosinephosphorylated p92. Previously we reported that Clnk became inducibly associated with a $92-\mathrm{kDa}$ tyrosine-phosphorylated polypeptide in response to immunoreceptor-mediated activation of $\mathrm{T}$ cells and myeloid cells (3). Since these cell types express both Clnk and SLP-76, we wanted to examine whether p92 was also associated with SLP-76. To this end, the IL-2dependent mouse T-cell line 5.32.5 (clone 2.5) was first activated with anti-CD3 MAb 145-2C11, and the differential capacities of Clnk and SLP-76 to interact with tyrosine-phosphorylated p92 were estimated by probing the relevant immunoprecipitates with antiphosphotyrosine antibodies (Fig. 1A). In agreement with our earlier report (3), we found that tyrosine-phosphorylated p92 was present in anti-Clnk immunoprecipitates obtained from activated cells (lane 2) but not from unstimulated cells (lane 1). In contrast, this product was not detected in SLP-76 immunoprecipitates from either unstimulated (lane 3) or stimulated (lane 4) cells, even though SLP-76 was clearly tyrosine phosphorylated and associated with the adaptor LAT in response to CD3 stimulation (lane 4). None of these polypeptides was present in immunoprecipitates obtained with normal rabbit serum (lanes 5 and 6).

The capacities of Clnk and SLP-76 to bind tyrosine-phosphorylated p92 were also compared by using the IL-3-dependent mouse myeloid cell line B6SutA $_{1}$ (Fig. 1B). Cells were activated via the high-affinity receptor for $\operatorname{IgG}(\mathrm{Fc} \gamma \mathrm{RI})$ by incubation with mouse $\operatorname{IgG}_{2 \mathrm{a}}$, and the interactions of Clnk and
SLP-76 with tyrosine-phosphorylated molecules were subsequently monitored as outlined for Fig. 1A. This experiment showed that while tyrosine-phosphorylated p92 became associated with Clnk in activated B6SutA 1 cells (Fig. 1B, lane 2), it did not detectably interact with SLP-76 (lane 6). In addition to p92, Clnk was also associated with a tyrosine-phosphorylated polypeptide of $\sim 130 \mathrm{kDa}$, both in unstimulated (Fig. 1B, lane 1) and in stimulated (lane 2) B6SutA $\mathrm{B}_{1}$ cells. A similar product was seen in SLP-76 immunoprecipitates (lanes 5 and 6). Our preliminary data indicate that this molecule is Fyb/SLAP-130, a previously described SLP-76 SH2 domain-binding protein (data not shown; see Fig. 3B for further evidence for this interaction) $(9,29)$.

Tyrosine-phosphorylated p92 interacts with the SH2 domain of Clnk. The preferential ability of p92 to interact with Clnk further suggested that this association may be relevant for Clnk-mediated functions. As an initial step towards the molecular identification of $\mathrm{p} 92$, it was important to understand better the structural basis for the association between these two molecules. Because p92 is tyrosine phosphorylated, one obvious possibility was that it interacted with Clnk by way of the Clnk $\mathrm{SH} 2$ region. To test this idea, GST fusion proteins encompassing the Clnk SH2 domain were produced in bacteria and immobilized on agarose-glutathione beads. They were subsequently assayed for their capacity to interact with p92 in vitro, using lysates obtained from resting or activated B6Sut $\mathrm{A}_{1}$ cells (Fig. 2).

An antiphosphotyrosine immunoblot showed that the $\mathrm{SH} 2$ region of Clnk was able to associate with a tyrosine-phosphorylated polypeptide of $\sim 92 \mathrm{kDa}$ present in stimulated cells (Fig. 2, lane 4) but not in resting cells (lane 3). This protein comigrated with the tyrosine-phosphorylated p92 found in anti-Clnk immunoprecipitates generated from activated cells (lane 12). Note that Clnk was constitutively tyrosine phosphor- 


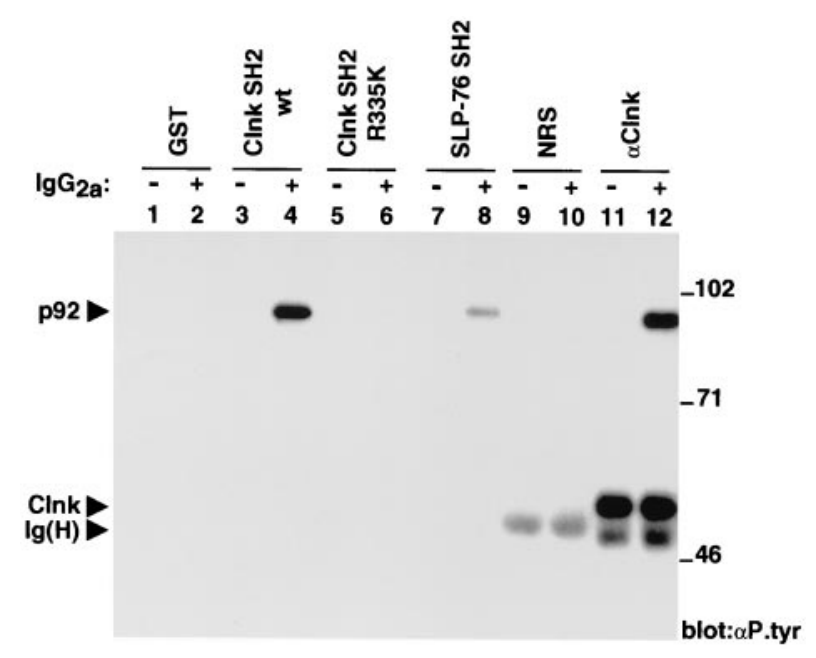

FIG. 2. Association of Clnk SH2 domain with tyrosine-phosphorylated p92. The abilities of various GST fusion proteins to associate with tyrosine-phosphorylated molecules from lysates of resting or activated B6SutA $_{1}$ cells were examined in an in vitro binding assay. Anti-Clnk $(\alpha$ Clnk) immunoprecipitates were also performed in parallel in order to reveal the migration of $\mathrm{p} 92$. The positions of prestained molecular weight markers are shown on the right; those of p92, Clnk, and heavy chain of $\operatorname{Ig}[\operatorname{Ig}(\mathrm{H})]$ are indicated on the left. Exposure, 48 h. $\alpha$ P.tyr, antiphosphotyrosine antibody; wt, wild type; NRS, normal rabbit serum.

ylated in this cell line (compare lanes 11 and 12), in agreement with an earlier report by members of our group (3). The ability of the Clnk SH2 domain to bind p92 in vitro was dramatically reduced by mutation of arginine 335 in the $\mathrm{SH} 2$ domain (arginine 335 to lysine 335 mutation) (lanes 5 and 6). This conserved residue is known to be required for phosphotyrosine binding in other SH2 domains (31). No tyrosine-phosphorylated product was complexed to GST alone (lanes 1 and 2). The capacity of the SH2 domain of SLP-76 to interact with p92 was also examined (lanes 7 and 8). Whereas we found that the SLP-76 SH2 domain was able to interact with tyrosine-phosphorylated p92 (lane 8), the extent of this association was significantly lower than that observed with the Clnk SH2 domain (lane 4). Titration experiments using serial dilutions of bacterial fusion proteins indicated that the $\mathrm{SH} 2$ region of SLP-76 interacted with tyrosine-phosphorylated p92 approximately 5 times less efficiently than the equivalent domain of Clnk (data not shown). This difference may explain our inability to observe p92 in anti-SLP-76 immunoprecipitates (Fig. 1). An anti-GST immunoblot confirmed that all GST fusion proteins used in this experiment were expressed in equivalent amounts (data not shown).

Cloning of putative Clnk-associated proteins using the yeast two-hybrid system. To identify the Clnk-associated p92, a yeast two-hybrid screen was performed using the Clnk SH2 domain as a bait. In order to permit tyrosine phosphorylation of potential partners, a modification of the yeast two-hybrid system in which the protein tyrosine kinase Src is also expressed in the yeast was used. Yeast cells expressing the $\mathrm{SH} 2$ region of Clnk were transformed with a mouse thymocyte cDNA library, and potential interacting proteins were identified as outlined in Materials and Methods. The most frequent clones identified in these assays corresponded to Fyb/SLAP-130 (data not shown) $(9,29)$. In addition, we found a single clone representing
A HPK-1

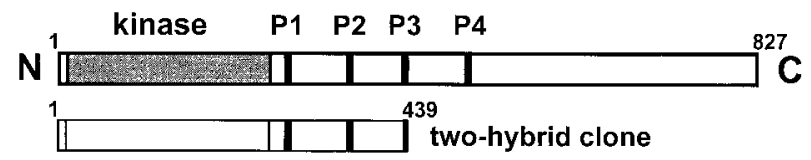

B

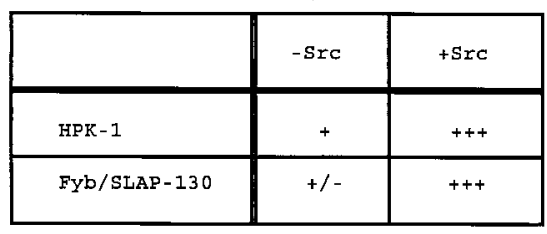

FIG. 3. Yeast two-hybrid screen. Potential binding proteins for the Clnk SH2 domain were identified using a yeast two-hybrid screen in the presence of the protein tyrosine kinase Src. (A) Identification of $h p k-1$ cDNA. The primary structure of HPK-1 and the corresponding segment identified in the yeast two-hybrid screen are shown. The positions of the kinase domain and proline-rich regions of HPK-1 are indicated. (B) Requirement of Src kinase activity for interaction of the Clnk SH2 domain with HPK-1 and Fyb/SLAP-130 in yeast. The abilities of HPK-1 (amino acids 1 to 439) and Fyb/SLAP-130 to associate with the SH2 domain of Clnk were assessed in yeast expressing $(+\mathrm{Src})$ or not expressing $(-\mathrm{Src})$ the Src kinase, as outlined in Materials and Methods. Yeast cells were tested for their capacity to produce $\beta$-galactosidase. +++ , green staining after $15 \mathrm{~min}$; + , green staining after $1 \mathrm{~h} ;+/-$, green staining after overnight incubation. Similar conclusions were reached when yeast cells were examined for the aptitude to grow in the absence of histidine (data not shown).

HPK-1, a serine/threonine protein kinase of $\sim 95 \mathrm{kDa}$ expressed in hemopoietic cells $(17,23)$. The region covered by this cDNA corresponded to the kinase domain and the proximal portion of the noncatalytic domain of mouse HPK-1 (amino-acids 1 to 439) (Fig. 3A). While little is known of the function of HPK-1 in hemopoietic cells, this kinase was recently shown to be activated and to undergo tyrosine phosphorylation in response to immunoreceptor engagement (26, 28). Our studies (Fig. 3B) also revealed that the interaction between the Clnk SH2 domain and HPK-1 in yeast was strongest in the presence of the Src kinase. Notably, though, a small degree of association also existed in yeast lacking the Src protein. Since yeast express little or no genuine protein tyrosine kinases, this observation suggested that the association between the SH2 domain of Clnk and HPK-1 may occur at a low level of efficiency in the absence of tyrosine phosphorylation. However, this interaction is clearly augmented by tyrosine phosphorylation.

Association of Clnk with HPK-1 in Cos-1 cells. Next, the ability of Clnk and HPK-1 to associate in mammalian cells was evaluated (Fig. 4). As a first step, Cos-1 cells were transiently transfected with cDNAs coding for mouse Clnk and HPK-1, in the absence or presence of the Src-related enzyme Lck. After $60 \mathrm{~h}$, cells were lysed in nonionic detergent-containing buffer, and the association between Clnk and HPK-1 was examined by immunoblotting of Clnk immunoprecipitates with anti-HPK-1 antibodies (Fig. 4A, top panel). This analysis revealed that in the absence of Clnk (lanes 1 to 4), no detectable HPK-1 was present in anti-Clnk immunoprecipitates. In contrast, abun- 
A

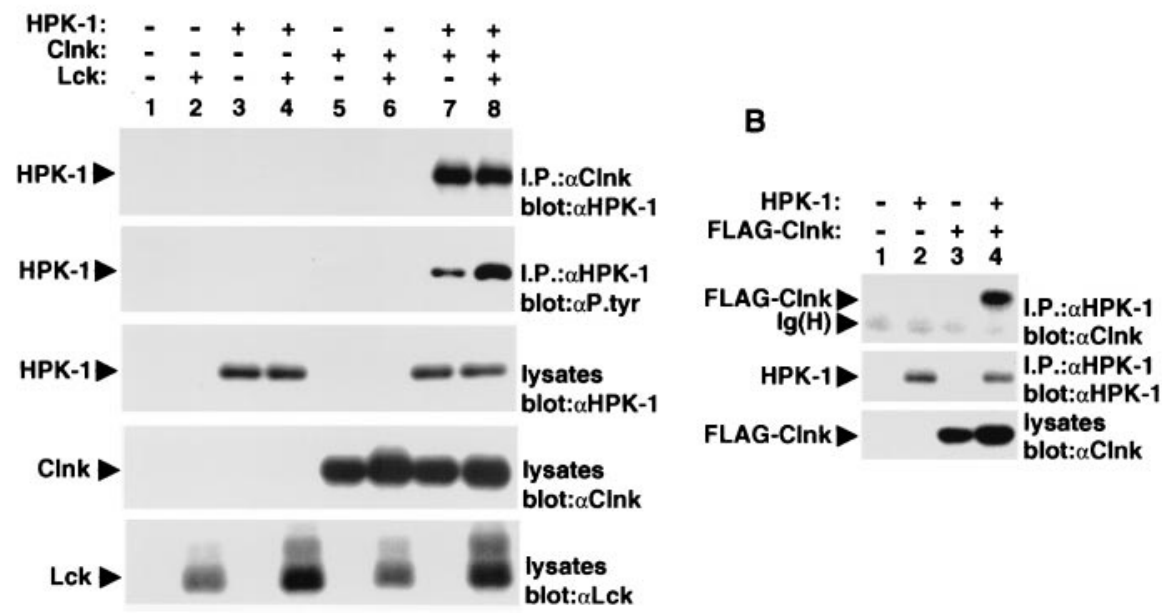

FIG. 4. Association of Clnk with HPK-1 in Cos-1 cells. (A) The ability of Clnk to associate with HPK-1 was examined by transient transfection in Cos-1 cells. An activated version of Lck (tyrosine 505 to phenylalanine 505; F505 Lck) was cotransfected in these cells in order to maximize protein tyrosine phosphorylation. The positions of HPK-1, Clnk, and Lck are shown on the left. Exposures: first panel, 3 h; second panel, 6 h; third panel, $3 \mathrm{~h}$; fourth panel, $3 \mathrm{~h}$; and fifth panel, 3 h. (B) Cos-1 cells were transiently transfected with cDNAs encoding HPK-1 and a FLAG-tagged version of Clnk (FLAG-Clnk). The association between HPK-1 and Clnk was then examined through probing of anti-HPK-1 ( $\alpha$ HPK-1) immunoprecipitates by anti-Clnk ( $\alpha$ Clnk) immunoblotting. The migrations of HPK-1, FLAG-Clnk, and heavy chain of $\operatorname{Ig}[\operatorname{Ig}(\mathrm{H})] \operatorname{are}$ indicated on the left. Exposures, 6 h. $\alpha$ P.tyr, antiphosphotyrosine antibody.

dant amounts of HPK-1 were recovered in Clnk immunoprecipitates generated from cells coexpressing Clnk and HPK-1 (lanes 7 and 8) but not in cells containing Clnk alone (lanes 5 and 6). The extent of the association between Clnk and HPK-1 was not influenced by coexpression of Lck (compare lanes 7 and 8).

In order to assess the phosphotyrosine content of HPK-1 in these cells, HPK-1 was isolated by immunoprecipitation with anti-HPK-1 antibodies and probed by immunoblotting with antiphosphotyrosine antibodies (Fig. 4A, second panel). In cells expressing HPK-1 without Clnk (lanes 3 and 4), the HPK-1 protein contained little or no phosphotyrosine, even in the presence of the Src-related kinase (lane 4). However, the phosphotyrosine content of HPK-1 was greatly augmented by expression of Clnk (lanes 7 and 8). While more pronounced HPK-1 tyrosine phosphorylation was noted in cells bearing Lck (lane 8), significant tyrosine phosphorylation was induced by Clnk in the absence of Lck (lane 7). Parallel immunoblots of total cell lysates with anti-HPK-1 (third panel), anti-Clnk (fourth panel), and anti-Lck (fifth panel) sera confirmed that all proteins were appropriately expressed.

The association between Clnk and HPK-1 was also probed by immunoblotting of HPK-1 immunoprecipitates with antiClnk antibodies (Fig. 4B). Cos-1 cells were transfected with a cDNA encoding HPK-1 in the absence or the presence of a cDNA coding for a variant of Clnk bearing a FLAG epitope at the amino terminus. A FLAG-tagged version of Clnk was used for these studies, as its electrophoretic migration could be more easily distinguished from that of the heavy chain of Ig. This analysis revealed that Clnk was detectable in anti-HPK-1 immunoprecipitates obtained from cells coexpressing HPK-1 (Fig. 4B, lane 4) but not from those lacking HPK-1 (lane 3).

The capacity of Clnk to bind HPK-1 was also compared to that of its relative SLP-76 (Fig. 5). For this purpose, cDNAs encoding FLAG-tagged variants of Clnk and SLP-76 were used in transient transfection assays as outlined for Fig. 4. The differential ability of FLAG-Clnk and FLAG-SLP-76 to associate with HPK-1 was ascertained by immunoblotting of FLAG immunoprecipitates with anti-HPK-1 antibodies (Fig. 5, first panel). This assay showed that in comparison to FLAG-Clnk (lanes 5 and 6), FLAG-SLP-76 (lanes 9 and 10) interacted poorly with HPK-1. While not evident in Fig. 5, a small degree of association between FLAG-SLP-76 and HPK-1 could be seen in longer autoradiographic exposures of this immunoblot (data not shown).

Interaction of Clnk with HPK-1 in hemopoietic cells. The aptitude of Clnk to interact physically with HPK-1 was also examined in hemopoietic cells (Fig. 6). To this end, the IL-2dependent mouse T-cell line 2.5 (Fig. 6A) and IL-3-dependent myeloid cell line $\mathrm{B}_{6} \mathrm{SutA}_{1}$ (Fig. 6B) were activated via their immunoreceptors as outlined for Fig. 1. The association between Clnk and HPK-1 was subsequently monitored by immunoblotting of Clnk immunoprecipitates with anti-HPK-1 antibodies. In both cell types (Fig. 6A and B), we found that small amounts of HPK-1 were associated with Clnk in unstimulated cells (lanes 1). However, the abundance of Clnk-associated HPK-1 was greatly augmented in response to immunoreceptor stimulation (lanes 2). When lysates were immunoprecipitated with anti-SLP-76 antibodies under conditions analogous to those described for Fig. 1, a detectable amount of associated HPK-1 was also noted in activated 2.5 cells (Fig. 6A, lane 6). In keeping with the results presented above, though, the extent of the SLP-76-HPK-1 interaction was much smaller than that of the Clnk-HPK-1 association. No HPK-1 was present in immunoprecipitates generated with normal rabbit serum (lanes 3 and 4). 

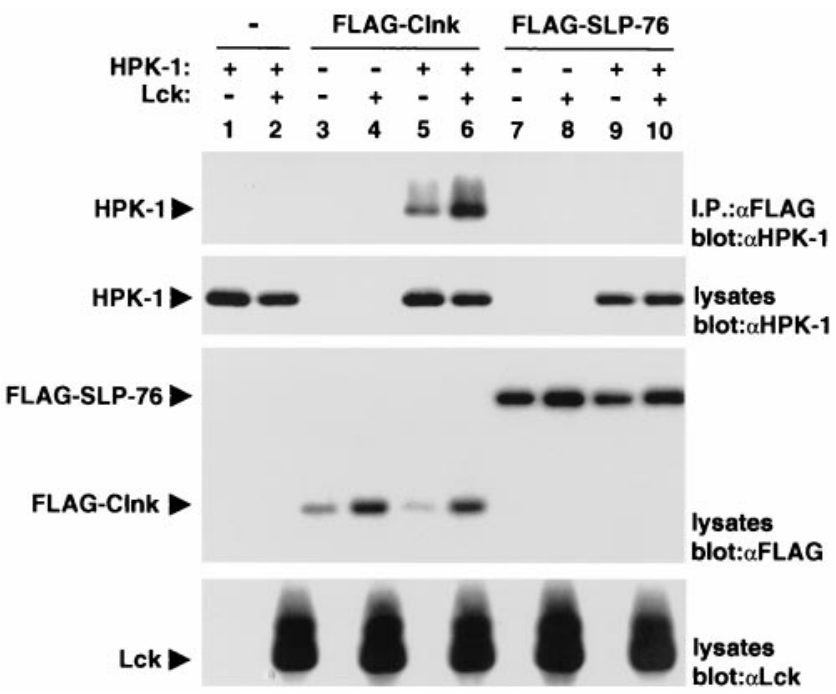

FIG. 5. Differential interactions of Clnk and SLP-76 with HPK-1 in Cos-1 cells. Experiments were done as outlined for Fig. 4, except that FLAG-tagged versions of Clnk and SLP-76 were used. The migrations of HPK-1, FLAG-Clnk, FLAP-SLP-76, and Lck are indicated on the left. Exposures: first panel, 16 h; second panel, 6 h; third panel, 16 h; and fourth panel, $6 \mathrm{~h}$. " $\alpha$ " designations indicate antibodies.

To ensure that the Clnk-associated tyrosine-phosphorylated p92 was HPK-1, reimmunoprecipitation experiments were performed (Fig. 6C). Clnk-associated proteins were first immunoprecipitated from activated $\mathrm{B}_{6} \mathrm{Sut}_{1}$ cells using anti-Clnk antibodies. After elution and denaturation in sample buffer, associated proteins were reimmunoprecipitated with either anti-HPK-1 antibodies or normal rabbit serum. Tyrosine-phosphorylated polypeptides were subsequently detected by immunoblotting with antiphosphotyrosine antibodies. This assay showed that a tyrosine-phosphorylated product comigrating with Clnk-associated p92 (lane 1) was detectable in immunoprecipitates generated with anti-HPK-1 antibodies (lane 2) but not with normal rabbit serum (lane 3 ). Thus, this result indicated that at least part of the Clnk-associated p92 was HPK-1. Unfortunately, the anti-HPK-1 sera available were not efficient at fully depleting HPK-1 from cell lysates (data not shown). Hence, we were not able to exclude formally the possibility that Clnk-associated p92 also represented additional polypeptides.

Cooperative enhancement of immunoreceptor-mediated IL2 promoter activation by Clnk and HPK-1. Previously, members of our group reported that Clnk was a strong positive regulator of antigen receptor-induced activation of the IL-2 promoter in Jurkat T cells (3). Hence, to provide insights into the function of the association between Clnk and HPK-1, the effect of coexpression of these two molecules in this system was examined. Jurkat cells were transiently transfected with cDNAs encoding either Clnk alone, HPK-1 alone, or both, in the presence of an IL-2-luciferase reporter plasmid. After $40 \mathrm{~h}$, cells were stimulated with anti-CD3 MAb OKT3, and the activation of the IL-2 promoter was monitored using a standard luciferase assay (Fig. 7).

This assay (Fig. 7A) revealed that introduction of Clnk alone caused an increase in CD3-mediated activation of the IL-2 promoter, in keeping with the earlier report (3). A smaller increase in IL-2 promoter activity was also observed in the absence of CD3 stimulation. In contrast, expression of HPK-1 alone had a weak, albeit reproducible, inhibitory effect on the activity of the IL-2-luciferase reporter, either in resting or in activated cells. Strikingly, though, the combination of Clnk and HPK-1 caused a more pronounced activation of the IL-2 promoter when contrasted with Clnk alone. In a series of independent experiments, the stimulation observed with Clnk and HPK-1 was two- to fivefold greater than that achieved by Clnk alone (Fig. 7; also data not shown). Immunoblots of total cell lysates with anti-HPK-1 (Fig. 7B, top panel) and anti-Clnk
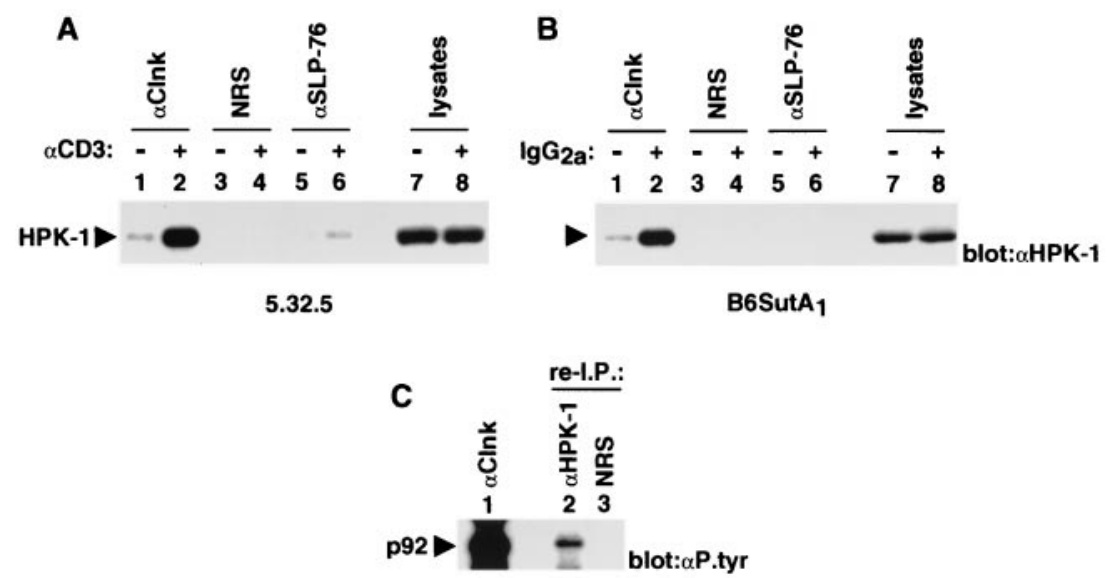

FIG. 6. Association of Clnk with HPK-1 in immunoreceptor-activated hemopoietic cells. (A and B) Experiments were performed as outlined for Fig. 1, except that polypeptides were probed by immunoblotting with anti-HPK-1 ( $\alpha$ HPK-1) antibodies. The position of HPK-1 is shown on the left. (A) IL-2-dependent antigen-specific T-cell line 2.5. Exposure, 16 h. (B) IL-3-dependent myeloid cell line B6SutA. Exposure, 6 h. (C) Reimmunoprecipitation (re-I.P.) experiment. Clnk was first immunoprecipitated from activated B6SutA 1 cells (lane 1). After elution and denaturation of associated proteins in sample buffer, polypeptides were reimmunoprecipitated from four combined anti-Clnk ( $\alpha$ Clnk) immunoprecipitates using the specified antibodies (lanes 2 and 3). Tyrosine-phosphorylated molecules were then detected by immunoblotting with anti-phosphotyrosine ( $\alpha$ P.tyr) antibodies. NRS, normal rabbit serum. The position of tyrosine-phosphorylated p92 is indicated on the left. Exposure, 4 days. 


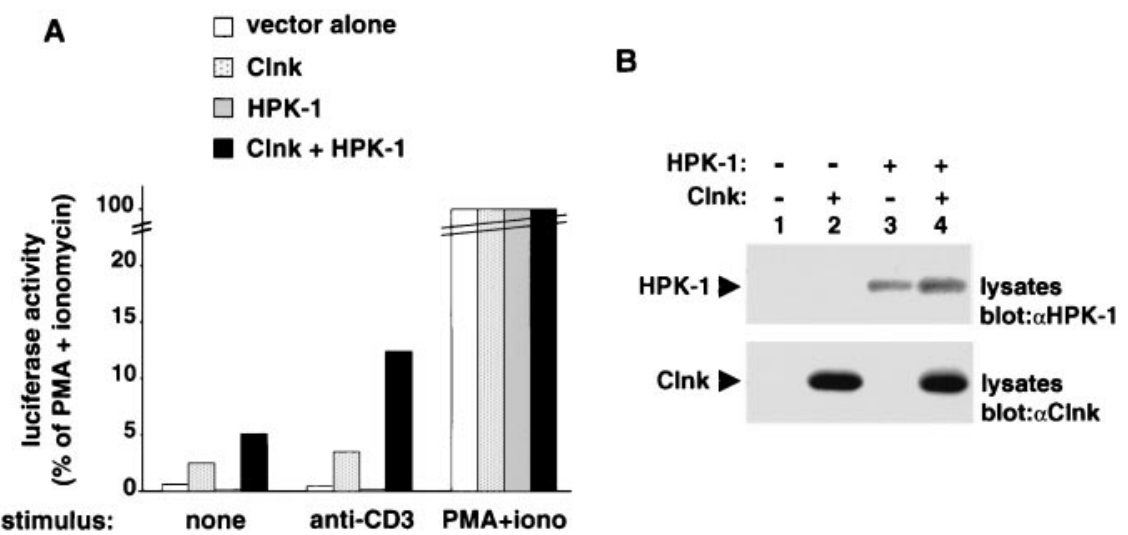

FIG. 7. Cooperative enhancement of T-cell antigen receptor signaling by Clnk and HPK-1. Jurkat Tag cells were transfected in duplicate with the indicated cDNAs in the presence of an IL-2 promoter-luciferase reporter plasmid. After $40 \mathrm{~h}$, cells were stimulated as described in Materials and Methods with either anti-CD3 MAb OKT3 (anti-CD3) or the combination of PMA and ionomycin (PMA+iono). (A) Luciferase assay. Luciferase activity is expressed as the percentages of values obtained in cells stimulated with PMA plus ionomycin. Assays were conducted in duplicate. The average value is shown. (B) Immunoblots. The expression levels of HPK-1 and Clnk were determined by immunoblotting of total cell lysates with the appropriate antisera (denoted by " $\alpha$ " designations). Exposures, $15 \mathrm{~h}$.

(bottom panel) confirmed that both proteins were adequately expressed in the various transfected populations.

To test whether endogenous HPK-1 molecules participated in the ability of Clnk to regulate antigen receptor signaling, the effect of coexpression of Clnk with a kinase-defective version of HPK-1 (K46E mutant) was evaluated (Fig. 8). While the mutant HPK-1 protein used in this experiment lacked intrinsic catalytic activity (23), it remained able to associate with Clnk (our unpublished results). Consequently, we believed that it might function as a dominant-interfering version of HPK-1.
The results of this assay (Fig. 8A) showed that by opposition to wild-type HPK-1, the kinase-defective version inhibited in a dose-dependent manner the ability of Clnk to up-regulate CD3-triggered activation of the IL-2 promoter. At the highest concentrations of kinase-inactive $h p k-1$ DNA used, the effect of Clnk was inhibited approximately fourfold. Importantly, parallel immunoblots of total cell lysates (Fig. 8B) demonstrated that introduction of the kinase-defective HPK-1 (lanes 4 to 7) did not interfere with the levels of expression of Clnk (bottom panel). It should be pointed out that the anti-mouse

A

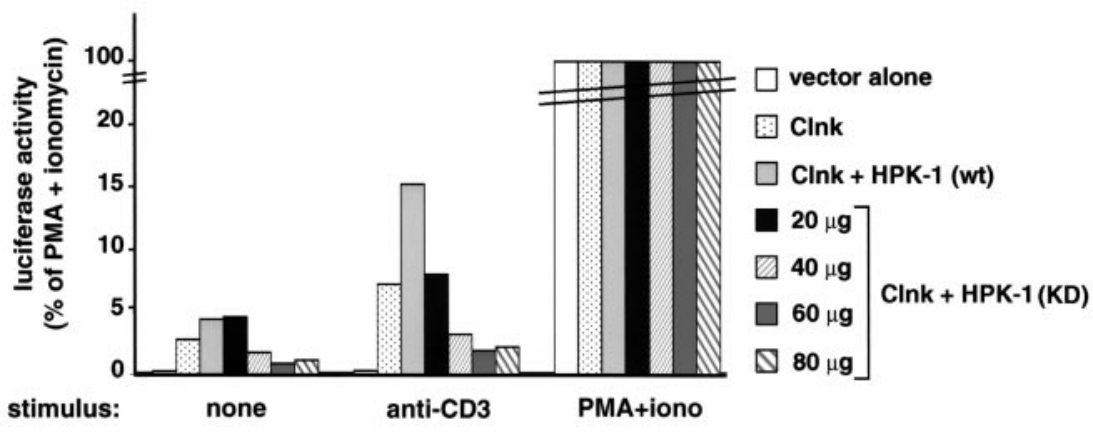

B

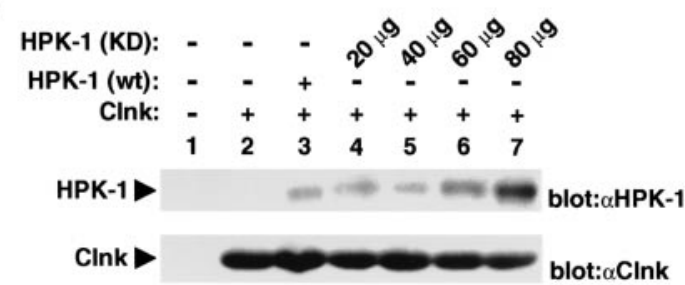

FIG. 8. Inhibition of Clnk-mediated impact on immunoreceptor signaling by kinase-inactive HPK-1. Experiments were performed as outlined in the legend for Fig. 7, except that either wild-type (wt) or kinase-defective (KD) HPK-1 was used. (A) Luciferase assay. Activity is expressed as the percentages of values obtained in cells stimulated with PMA plus ionomycin. The average value of duplicates is shown. Expression of kinase-defective HPK-1 alone had no appreciable effect on IL-2 promoter activation in Jurkat T cells (data not shown). (B) Immunoblots. The expression levels of HPK-1 and Clnk were determined by immunoblotting of total cell lysates with the indicated antisera (" $\alpha$ " designations). Exposures, $20 \mathrm{~h}$. 
A
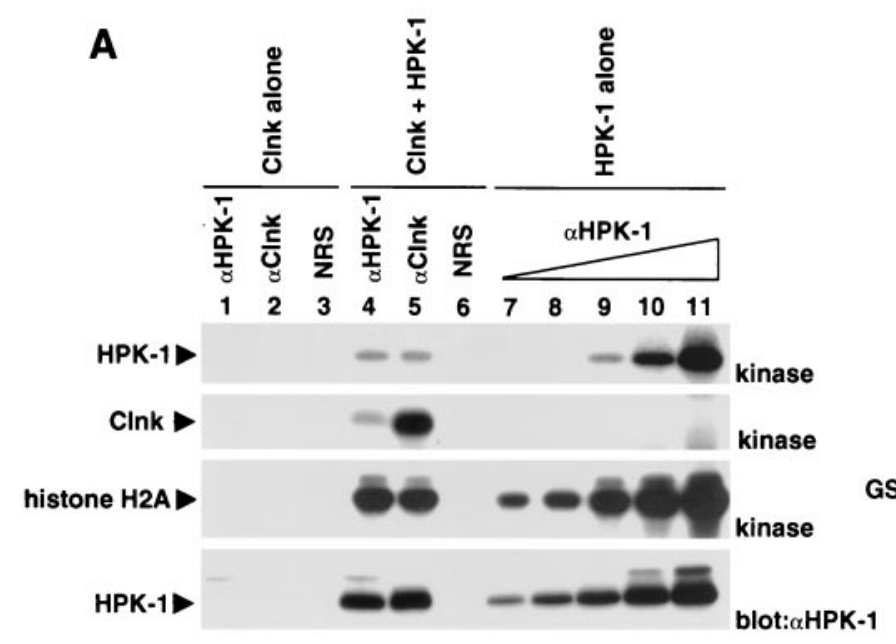

B

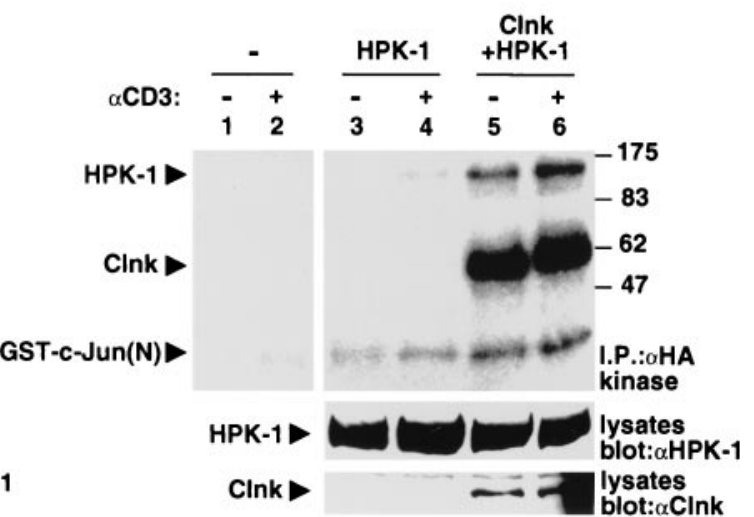

FIG. 9. Effect of Clnk on the kinase activity of HPK-1. (A) Transient transfection in Cos-1 cells. Cos-1 cells were transiently transfected with the indicated cDNAs. After immunoprecipitation with either anti-HPK-1 $(\alpha$ HPK-1) or anti-Clnk $(\alpha$ Clnk) antibodies, the catalytic activity of HPK-1 was measured in immune-complex kinase reactions, using histone $\mathrm{H} 2 \mathrm{~A}$ as an exogenous substrate (first, second, and third panels). All reactions were performed under linear assay conditions (data not shown). The abundance of HPK-1 in the immunoprecipitates was verified by immunoblotting of parallel immunoprecipitates with HPK-1 antibodies (fourth panel). The expression of Clnk was verified by immunoblotting of total cell lysates with anti-Clnk antibodies and was found to be adequate (data not shown). The following amounts of total cellular proteins were used for immunoprecipitation: lanes 1 and 4,250 $\mu \mathrm{g}$; lanes 2, 3, 5, and 6, $500 \mu \mathrm{g}$; lane 7, 31.3 $\mu \mathrm{g}$; lane 8, $62.5 \mu \mathrm{g}$; lane 9, $125 \mu \mathrm{g}$; lane 10, $250 \mu \mathrm{g}$; and lane 11, $500 \mu \mathrm{g}$. NRS, normal rabbit serum. The migrations of HPK-1, Clnk, and histone H2A are indicated on the left. Exposures: first, second, and third panels, $12 \mathrm{~h}$; fourth panel, $4 \mathrm{~h}$. (B) Transient transfection in Jurkat cells. Cells were transiently transfected with the indicated cDNAs. After $48 \mathrm{~h}$, they were stimulated or not stimulated for $3 \mathrm{~min}$ with anti-CD3 MAb OKT3, and the kinase activity of HPK-1 was measured in immune-complex kinase reactions, using the amino-terminal portion of c-Jun [GST-c-Jun(N)] as an exogenous substrate. The positions of prestained molecular mass markers are shown on the right; those of HPK-1, Clnk, and GST-c-Jun(N) are indicated on the left.

HPK-1 sera used did not react efficiently with the endogenous human HPK-1 present in Jurkat cells, explaining its lack of detection in these immunoblots (top panel, lanes 1 and 2). Hence, altogether, the results of Fig. 7 and 8 indicated that Clnk and HPK-1 cooperated to enhance antigen receptorinduced signaling events in Jurkat $\mathrm{T}$ cells and that this effect necessitated the enzymatic activity of HPK-1.

Impact of CInk on the kinase activity of HPK-1. In a previous report (26), it was shown that HPK-1 alone had a moderate inhibitory impact on TCR-induced activation of AP-1 in Jurkat cells. In a related way, we consistently observed that HPK-1 by itself provoked a small reduction in TCR-driven IL-2 promoter activation (Fig. 7; also data not shown). Since addition of HPK-1 to Clnk had a stimulatory rather than inhibitory effect on IL-2 promoter activation (Fig. 7), we wanted to assess the possibility that Clnk had an impact on the catalytic activity of HPK-1. To test the effect of Clnk on the basal activity of HPK-1, HPK-1 was transiently expressed in Cos-1 cells, with or without Clnk. The kinase activity of HPK-1 was subsequently measured in immune-complex kinase reactions, using either HPK-1 or Clnk immunoprecipitates (Fig. 9A). All reactions were performed under linear assay conditions in the presence of the exogenous substrate histone $\mathrm{H} 2 \mathrm{~A}$. This study revealed that the ability of HPK-1 to undergo autophosphorylation (first panel) or phosphorylate histone $\mathrm{H} 2 \mathrm{~A}$ (third panel) was not significantly altered by expression or binding of Clnk. It was also observed that Clnk underwent prominent phosphorylation during the kinase reaction in cells expressing HPK-1 (second panel, lane 5). This observation suggested that Clnk is a substrate for HPK-1.
We also examined the impact of Clnk on the ability of HPK-1 to undergo enzymatic activation during T-cell activation (Fig. 9B). Jurkat cells were transiently transfected with HA-tagged HPK-1, in the presence or the absence of Clnk. After 48 h, cells were stimulated with anti-CD3 MAb OKT3, and the kinase activity of HPK-1 was determined in immunecomplex kinase reactions, using the amino-terminal domain of c-Jun as an exogenous substrate. As reported elsewhere (26, 28), HPK-1 alone exhibited a detectable increase in kinase activity upon antigen receptor stimulation (top panel, lanes 3 and 4). By comparison, in the presence of Clnk (lanes 5 and 6), the activity of HPK-1 was greatly enhanced, both in unstimulated (lane 5) and in stimulated (lane 6) cells. Hence, it is unlikely that the observed synergism between Clnk and HPK-1 on TCR-induced IL-2 promoter activation resulted from an allosteric inhibition of the catalytic activity of HPK-1. Rather, it appears that Clnk facilitated the activation of HPK-1 in response to TCR stimulation.

Clnk can functionally substitute for SLP-76 in immunoreceptor signaling. The findings described herein and elsewhere indicate that Clnk and SLP-76 interact with distinct sets of cellular proteins. Namely, SLP-76 forms complexes with Vav, Nck, GADS, and Fyb. With the exception of Fyb (this report; also our unpublished results), we found that none of these other partners associated with Clnk in hemopoietic cells. By contrast, Clnk interacted strongly with HPK-1. A much weaker association existed between SLP-76 and HPK-1. Notwithstanding, we reported that Clnk was able to augment antigen receptor-induced activation of NFAT, AP-1, and IL-2 promoter in Jurkat $\mathrm{T}$ cells in a manner analogous to that of SLP-76 (3). 


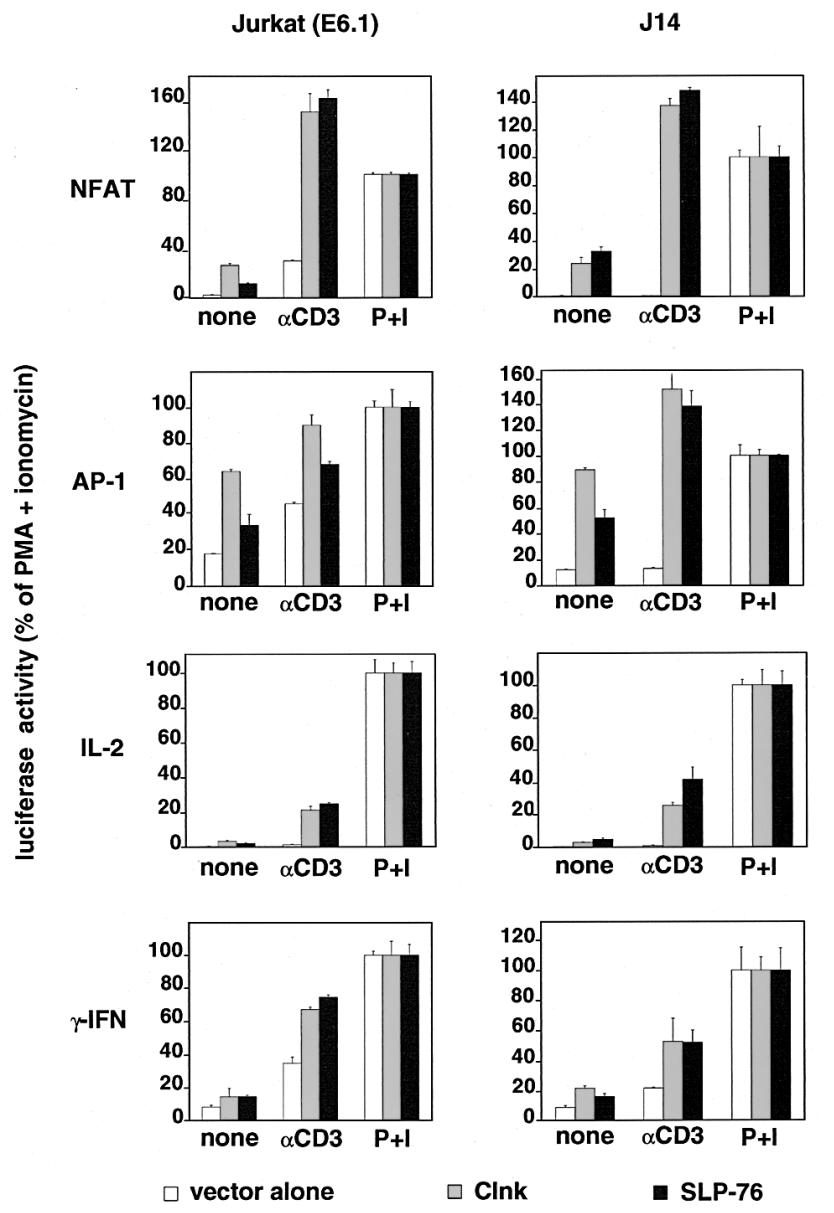

FIG. 10. Rescue of antigen receptor signaling in a SLP-76-deficient T-cell line by Clnk. Parental Jurkat cells (clone E6.1) and a SLP-76deficient variant (J14) were transfected with cDNAs encoding either Clnk or SLP-76, in the presence of the indicated luciferase reporter plasmids. Cells were subsequently activated, and luciferase activity was monitored, as detailed in Materials and Methods. Results are represented as percentages of values obtained with PMA plus ionomycin. All assays were done in duplicate. Average values with ranges are shown.

Thus, Clnk and SLP-76 may have similar impacts on the downstream events of T-cell activation, albeit through distinct biochemical mechanisms.

To address further the functional similarities between Clnk and SLP-76 in immunoreceptor signaling, we wanted to test the ability of Clnk to rescue antigen receptor-mediated responses in a SLP-76-deficient variant of Jurkat (J14) (44) (Fig. 10). J14 or parental Jurkat E6.1 cells were transiently transfected with cDNAs encoding either Clnk or SLP-76, in the presence of an NFAT-luciferase, AP-1-luciferase, IL-2 promoter-luciferase, or IFN- $\gamma$ promoter-luciferase reporter. Antigen receptor-induced reporter gene activation was subsequently measured as detailed in Materials and Methods. In keeping with earlier findings of members of our group (3), it was noted that expression of either Clnk or SLP-76 in parental Jurkat cells provoked a strong increase in the CD3-mediated activation of NFAT, AP-1, IL-2 promoter, and IFN- $\gamma$ promoter (Fig. 10). An enhancement of reporter gene activity was also observed in the absence of antigen receptor stimulation. As described by others (44), we also found that SLP-76-deficient J14 cells transfected with empty vector failed to activate any of the luciferase reporters in response to CD3 stimulation. This defect was corrected by reintroduction of SLP-76. Interestingly, expression of Clnk was also able to rescue antigen receptor-induced transcriptional events in J14 cells, in a manner similar to that of SLP-76. Therefore, despite their abilities to interact with different sets of proteins, Clnk and SLP-76 can be functionally analogous, at least in Jurkat $\mathrm{T}$ cells.

\section{DISCUSSION}

Herein, we attempted to identify a $92-\mathrm{kDa}$ tyrosine-phosphorylated protein that selectively interacts with Clnk in immunoreceptor-activated $\mathrm{T}$ cells and myeloid cells (3). In a yeast two-hybrid screen using the Clnk $\mathrm{SH} 2$ region as a bait, evidence was adduced that $\mathrm{p} 92$ may be HPK-1, a serine/threonine protein kinase expressed in hemopoietic cells $(17,23,26)$. Experiments using transiently transfected Cos-1 cells and cytokine-dependent hemopoietic cells confirmed that Clnk was also associated with HPK-1 in mammalian cells and that this association was induced by immune cell activation. By comparison, SLP-76 interacted much less extensively with HPK-1. Cotransfection studies in Jurkat T cells revealed that Clnk and HPK-1 synergized to enhance immunoreceptor-mediated activation of the IL-2 promoter. Moreover, the ability of Clnk to stimulate IL-2 promoter activity was inhibited by expression of a catalytically inactive version of HPK-1. Finally, we found that despite the affinities of Clnk and SLP-76 for distinct sets of cellular proteins, Clnk was able to substitute functionally for SLP-76 in a SLP-76-deficient T-cell line.

HPK-1 is a member of the germinal center kinase family of serine/threonine protein kinases (25). It contains an aminoterminal catalytic domain as well as a long carboxy-terminal extension bearing several proline-rich sequences capable of binding SH3 domains, one or more putative sites of tyrosine phosphorylation, and a citron homology domain. Like other members of the germinal center kinase family, HPK-1 is capable of activating the stress-activated protein kinase cascade via MAPK kinase kinases (23). More recent studies suggested that HPK-1 is also able to stimulate NF-кB by a distinct, albeit poorly understood, mechanism $(2,18)$. Whereas little is known of the role of HPK-1 in immunoreceptor signaling, it was recently published that HPK-1 becomes enzymatically activated in response to immunoreceptor stimulation in T cells and B cells $(26,28)$. This activation was found to be dependent on expression of SLP-76, LAT, and members of the Grb2 family $(26,28)$.

In this report, we found that HPK-1 became inducibly associated with Clnk in response to immunoreceptor stimulation in $\mathrm{T}$ cells and myeloid cells. In addition, it was observed that HPK-1 cooperated with Clnk to facilitate activation of the IL-2 promoter in response to antigen receptor stimulation in Jurkat $\mathrm{T}$ cells. Hence, these results indicated that in the presence of Clnk, HPK-1 seemed to have a positive regulatory role in immunoreceptor signaling. It is noteworthy, however, that overexpression of HPK-1 alone had a weak inhibitory effect on IL-2 promoter activation in Jurkat cells. Likewise, Liou et al. (26) reported that overexpression of HPK-1 alone caused an 
inhibition, rather than stimulation, of TCR-induced AP-1 activation in the same cell line. A similar finding was made in our laboratory (data not shown). We do not trust that the opposite effects of HPK-1 in the absence and the presence of Clnk can be simply explained by a Clnk-mediated repression of the kinase activity of HPK-1. Indeed, the stimulatory effect of Clnk and HPK-1 on IL-2 promoter activation was consistently greater, not smaller, than that of Clnk alone. Moreover, in Cos-1 cells, Clnk expression and binding had little or no effect on the kinase activity of HPK-1, as measured in immunecomplex kinase reactions. Lastly, expression of Clnk in Jurkat $\mathrm{T}$ cells actually caused an increase in the kinase activity of HPK-1.

On the basis of these results, we believe that Clnk influences the function of HPK-1 in two ways. First, its presence results in an increase in the kinase activity of HPK-1 in T cells. While the mechanism of this activation remains to be determined, it is likely to require additional components present in T cells, since a similar activation was not observed in Cos- 1 cells. Second, Clnk seems to allow HPK-1 to participate in a signaling pathway that is qualitatively distinct from that used by HPK-1 alone. As a result, HPK-1 becomes a positive regulator rather than an inhibitor of IL-2 promoter activation. This modification may be due to a Clnk-mediated change in HPK-1 cellular localization or, alternatively, to a modification in its substrate specificity.

The exact mechanism by which Clnk and HPK-1 up-regulate IL-2 promoter activity remains to be clarified. Since the ability of HPK-1 to synergize with Clnk was dependent on its catalytic activity, it seems likely that HPK-1 functions by phosphorylating specific intracellular targets. In earlier studies $(2,18,23)$, it was shown that HPK-1 could activate the stress-activated protein kinase pathway and NF- $\mathrm{B}$ in a variety of cell types. Thus, it is plausible that the Clnk-HPK-1 complex is also coupled to these pathways during immunoreceptor signaling. Alternatively, Clnk may allow HPK-1 to be involved in another as yet unappreciated cascade. Clearly, additional experiments are required to explore these possibilities.

In addition to HPK-1, Clnk is likely to interact with other cellular molecules. Along these lines, we have already demonstrated that Clnk (like SLP-76) can associate with Fyb/SLAP130, an adaptor molecule implicated in cytoskeletal reorganization $(19,24)$. It is notable, however, that this interaction was not consistently seen in all cells and was independent of immunoreceptor engagement. Furthermore, even though Clnk does not bind Vav, Nck, or GADS, it possesses sites of tyrosine phosphorylation and proline-rich regions that presumably mediate associations with other SH2 domain- or SH3 domaincontaining molecules (3). Notwithstanding these alternative associations, the interaction with HPK-1 appears pivotal for the ability of Clnk to promote immunoreceptor signaling. This notion is supported by the observation that expression of a kinase-defective version of HPK-1 caused a significant reduction in the capacity of Clnk to enhance IL-2 promoter activation in Jurkat $\mathrm{T}$ cells.

Intriguingly, expression of Clnk was able to augment the extent of tyrosine phosphorylation of HPK-1 in Cos- 1 cells. Similar findings were made with a T-cell line engineered to overexpress Clnk in a stable manner (our unpublished results). One possible interpretation for these findings is that binding of the $\mathrm{SH} 2$ domain of Clnk to one or more sites of tyrosine phosphorylation on HPK-1 protected these sites from the action of protein tyrosine phosphatases. A similar situation has been documented for other SH2 domains $(35,40)$. Alternatively, Clnk might allow the recruitment of PTKs capable of phosphorylating HPK-1 on additional tyrosine residues. This "processive" phosphorylation could permit the binding of HPK-1 to other SH2 domain-containing molecules. Although the site(s) and the function(s) of HPK-1 tyrosine phosphorylation are not identified, the ability of Clnk to promote HPK-1 tyrosine phosphorylation could represent an additional mechanism by which it regulates the function of HPK-1 in immunoreceptor signaling.

Both the in vitro binding studies and the yeast two-hybrid screen indicated that the $\mathrm{SH} 2$ domain of Clnk was likely involved in mediating the interaction with HPK-1. This domain probably recognizes sites of tyrosine phosphorylation on HPK-1. Nevertheless, it should be pointed out that deletion of the Clnk SH2 domain caused only a partial $(\sim 75 \%)$ reduction in the ability of Clnk to bind HPK-1 in Cos- 1 cells (our unpublished results). Thus, it is probable that additional sequences participated in the Clnk-HPK-1 interaction. The existence of at least two points of contact between Clnk and HPK-1 may help secure their association in activated hemopoietic cells. Experiments are currently under way to define precisely the mechanism of association between Clnk and HPK-1.

Typically, hemopoietic cells expressing Clnk, like cytokinestimulated T cells, NK cells, mast cells, and myeloid cells, also contain SLP-76. On this basis, it would appear unlikely that the purposes of Clnk and SLP-76 in these cells are identical. The differential abilities of these two molecules to bind cellular partners offers further support for this idea. Surprisingly, however, we found that Clnk was capable of restoring antigen receptor-induced transcriptional events in a Jurkat T-cell variant lacking SLP-76, in a manner analogous to that of SLP-76. These seemingly contradictory observations could be reconciled by proposing that Clnk and SLP-76 can enhance immunoreceptor signaling in similar ways but by using distinct sets of partners. Some of the requirements for immunoreceptor signaling (such as the formation of proper SLP-76-GADS-LAT complexes in T cells) may be alleviated in the presence of Clnk. Hence, the presence of Clnk in cytokine-stimulated cells may serve to facilitate cell activation. In T cells, this property could translate into diminished requirements for engagement of coreceptors (CD4 and $\mathrm{CD} 8$ ) and costimulatory molecules (like CD28), as has been described for memory cells (21). In a related manner, Clnk could regulate mast cell reactivity and lymphokine-activated natural killing. These possibilities deserve consideration.

In summary, our data show that the SLP-76-related adaptor molecule Clnk physically and functionally interacts with HPK-1 in immunoreceptor-activated hemopoietic cells. They also indicate that Clnk has the capacity to substitute at least partially for SLP-76 during immunoreceptor signaling, even though it binds to a distinct set of partners. In light of these findings, a formal evaluation of the role of Clnk in hemopoietic cell functions and homeostasis through the creation of Clnkdeficient mice seems warranted. 


\section{ACKNOWLEDGMENTS}

We thank Art Weiss and Gary Koretzky for gifts of reagents. This work was supported by grants from the National Cancer Institute of Canada, the Canadian Institutes of Health Research and Valorisation Recherche Québec, to A.V. C.R. held a Fellowship from the Fondation pour la Recherche Médicale (France), while J.D.R. is the recipient of a Studentship from the Canadian Institutes of Health Research. A.V. is a Senior Scientist of the Canadian Institutes of Health Research.

\section{REFERENCES}

1. Abraham, N., M. C. Miceli, J. R. Parnes, and A. Veillette. 1991. Enhancement of T-cell responsiveness by the lymphocyte-specific tyrosine protein kinase p56 ${ }^{\text {lck }}$. Nature 350:62-66.

2. Arnold, R., J. Liou, H. C. A. Drexler, A. Weiss, and F. Kiefer. 2001. Caspasemediated cleavage of hematopoietic progenitor kinase 1 (HPK1) converts an activator of NFKB into an inhibitor of NFkB. J. Biol. Chem. 276:1467514684.

3. Cao, M. Y., D. Davidson, J. Yu, S. Latour, and A. Veillette. 1999. Clnk, a novel SLP-76-related adaptor molecule expressed in cytokine-stimulated hemopoietic cells. J. Exp. Med. 190:1527-1534.

4. Chan, A. C., D. M. Desai, and A. Weiss. 1994. The role of protein tyrosine kinases and protein tyrosine phosphatases in $\mathrm{T}$ cell antigen receptor signal transduction. Annu. Rev. Immunol. 12:555-592.

5. Clements, J. L., and G. A. Koretzky. 1999. Recent developments in lymphocyte activation: linking kinases to downstream signaling events. J. Clin. Investig. 103:925-929.

6. Clements, J. L., S. E. Ross-Barta, L. T. Tygrett, T. J. Waldschmidt, and G. A Koretzky. 1998. SLP-76 expression is restricted to hemopoietic cells of monocyte, granulocyte, and T lymphocyte lineage and is regulated during $\mathrm{T}$ cell maturation and activation. J. Immunol. 161:3880-3889.

7. Clements, J. L., B. Yang, S. E. Ross-Barta, S. L. Eliason, R. F. Hrstka, R. A. Williamson, and G. A. Koretzky. 1998. Requirement for the leukocytespecific adapter protein SLP-76 for normal T cell development. Science 281:416-419.

8. Cloutier, J. F., and A. Veillette. 1996. Association of inhibitory tyrosine protein kinase $\mathrm{p} 50^{\mathrm{csk}}$ with protein tyrosine phosphatase PEP in T cells and other hemopoietic cells. EMBO J. 15:4909-4918.

9. da Silva, A. J., Z. Li, C. de Vera, E. Canto, P. Findell, and C. E. Rudd. 1997. Cloning of a novel T-cell protein FYB that binds FYN and SH2-domaincontaining leukocyte protein 76 and modulates interleukin 2 production. Proc. Natl. Acad. Sci. USA 94:7493-7498.

10. Davidson, D., L. M. Chow, M. Fournel, and A. Veillette. 1992. Differential regulation of $\mathrm{T}$ cell antigen responsiveness by isoforms of the src-related tyrosine protein kinase p59fyn. J. Exp. Med. 175:1483-1492.

11. Fournel, M., D. Davidson, R. Weil, and A. Veillette. 1996. Association of tyrosine protein kinase Zap-70 with the protooncogene product $\mathrm{p} 120^{\mathrm{c}-\mathrm{cbl}}$ in T lymphocytes. J. Exp. Med. 183:301-306.

12. Fu, C., C. W. Turck, T. Kurosaki, and A. C. Chan. 1998. BLNK: a central linker protein in B cell activation. Immunity 9:93-103.

13. Goitsuka, R., Y. Fujimura, H. Mamada, A. Umeda, T. Morimura, K. Uetsuka, K. Doi, S. Tsuji, and D. Kitamura. 1998. BASH, a novel signaling molecule preferentially expressed in B cells of the bursa of Fabricius. J. Immunol. 161:5804-5808.

14. Goitsuka, R., H. Kanazashi, H. Sasanuma, Y. Fujimura, Y. Hidaka, A. Tatsuno, C. Ra, K. Hayashi, and D. Kitamura. 2000. A BASH/SLP-76related adaptor protein MIST/Clnk involved in IgE receptor-mediated mast cell degranulation. Int. Immunol. 12:573-580.

15. Haughn, L., S. Gratton, L. Caron, R. P. Sekaly, A. Veillette, and M. Julius. 1992. Association of tyrosine kinase $\mathrm{p} 56^{\mathrm{lck}}$ with CD4 inhibits the induction of growth through the alpha beta T-cell receptor. Nature 358:328-331.

16. Hayashi, K., R. Nittono, N. Okamoto, S. Tsuji, Y. Hara, R. Goitsuka, and D. Kitamura. 2000. The B cell-restricted adaptor BASH is required for normal development and antigen receptor-mediated activation of B cells. Proc. Natl. Acad. Sci. USA 97:2755-2760.

17. Hu, M. C., W. R. Qiu, X. Wang, C. F. Meyer, and T. H. Tan. 1996. Human HPK1, a novel human hematopoietic progenitor kinase that activates the JNK/SAPK kinase cascade. Genes Dev, 10:2251-2264.

18. Hu, M. C., Y. Wang, W. R. Qiu, A. Mikhail, C. F. Meyer, and T. H. Tan. 1999. Hematopoietic progenitor kinase-1 (HPK1) stress response signaling pathway activates IkappaB kinases (IKK-alpha/beta) and IKK-beta is a developmentally regulated protein kinase. Oncogene 18:5514-5524.

19. Hunter, A. J., N. Ottoson, N. Boerth, G. A. Koretzky, and Y. Shimizu. 2000. Cutting edge: a novel function for the SLAP-130/FYB adapter protein in beta 1 integrin signaling and T lymphocyte migration. J. Immunol. 164:11431147.
20. Jackman, J. K., D. G. Motto, Q. Sun, M. Tanemoto, C. W. Turck, G. A. Peltz, G. A. Koretzky, and P. R. Findell. 1995. Molecular cloning of SLP-76, a 76-kDa tyrosine phosphoprotein associated with Grb2 in T cells. J. Biol. Chem. 270:7029-7032.

21. Jenkins, M. K., A. Khoruts, E. Ingulli, D. L. Mueller, S. J. McSorley, R. L. Reinhardt, A. Itano, and K. A. Pape. 2001. In vivo activation of antigen specific CD4 T cells. Annu. Rev. Immunol. 19:23-45.

22. Jumaa, H., B. Wollscheid, M. Mitterer, J. Wienands, M. Reth, and P. J. Nielsen. 1999. Abnormal development and function of B lymphocytes in mice deficient for the signaling adaptor protein SLP-65. Immunity 11:547554.

23. Kiefer, F., L. A. Tibbles, M. Anafi, A. Janssen, B. W. Zanke, N. Lassam, T. Pawson, J. R. Woodgett, and N. N. Iscove. 1996. HPK1, a hematopoietic protein kinase activating the SAPK/JNK pathway. EMBO J. 15:7013-7025.

24. Krause, M., A. S. Sechi, M. Konradt, D. Monner, F. B. Gertler, and J. Wehland. 2000. Fyn-binding protein (Fyb)/SLP-76-associated protein (SLAP), Ena/vasodilator-stimulated phosphoprotein (VASP) proteins and the Arp2/3 complex link $T$ cell receptor (TCR) signaling to the actin cytoskeleton. J. Cell Biol. 149:181-194.

25. Kyriakis, J. M. 1999. Signaling by the germinal center kinase family of protein kinases. J. Biol. Chem. 274:5259-5262.

26. Liou, J., F. Kiefer, A. Dang, A. Hashimoto, M. H. Cobb, T. Kurosaki, and A. Weiss. 2000. HPK1 is activated by lymphocyte antigen receptors and negatively regulates AP-1. Immunity 12:399-408.

27. Lioubin, M. N., P. A. Algate, S. Tsai, K. Carlberg, A. Aebersold, and L. R. Rohrschneider. 1996. p150 ${ }^{\text {Ship }}$, a signal transduction molecule with inositol polyphosphate-5-phosphatase activity. Genes Dev. 10:1084-1095.

28. Liu, S. K., C. A. Smith, R. Arnold, F. Kiefer, and C. J. McGlade. 2000. The adaptor protein Gads (Grb2-related adaptor downstream of Shc) is implicated in coupling hemopoietic progenitor kinase-1 to the activated TCR. J. Immunol. 165:1417-1426.

29. Marie-Cardine, A., L. R. Hendricks-Taylor, N. J. Boerth, H. Zhao, B. Schraven, and G. A. Koretzky. 1998. Molecular interaction between the Fyn-associated protein SKAP55 and the SLP-76-associated phosphoprotein SLAP-130. J. Biol. Chem. 273:25789-25795.

30. Pappu, R., A. M. Cheng, B. Li, Q. Gong, C. Chiu, N. Griffin, M. White, B. P. Sleckman, and A. C. Chan. 1999. Requirement for B cell linker protein (BLNK) in B cell development. Science 286:1949-1954.

31. Pawson, T., and G. D. Gish. 1992. SH2 and SH3 domains: from structure to function. Cell 71:359-362.

32. Peri, K. G., F. G. Gervais, R. Weil, D. Davidson, G. D. Gish, and A. Veillette. 1993. Interactions of the SH2 domain of lymphocyte-specific tyrosine protein kinase $\mathrm{p} 56^{\mathrm{lck}}$ with phosphotyrosine-containing proteins. Oncogene 8:27652772

33. Peri, K. G., and A. Veillette. 1994. Tyrosine protein kinases in T lymphocytes. Chem. Immunol. 59:19-39.

34. Pivniouk, V., E. Tsitsikov, P. Swinton, G. Rathbun, F. W. Alt, and R. S. Geha. 1998. Impaired viability and profound block in thymocyte development in mice lacking the adaptor protein SLP-76. Cell 94:229-238.

35. Rotin, D., B. Margolis, M. Mohammadi, R. J. Daly, G. Daum, N. Li, E. H. Fischer, W. H. Burgess, A. Ullrich, and J. Schlessinger. 1992. SH2 domains prevent tyrosine dephosphorylation of the EGF receptor: identification of Tyr992 as the high-affinity binding site for $\mathrm{SH} 2$ domains of phospholipase $\mathrm{C}$ gamma. EMBO J. 11:559-567.

36. Rudd, C. E. 1999. Adaptors and molecular scaffolds in immune cell signaling. Cell 96:5-8.

37. Tamir, I., and J. C. Cambier. 1998. Antigen receptor signaling: integration of protein tyrosine kinase functions. Oncogene 17:1353-1364.

38. Tomlinson, M. G., J. Lin, and A. Weiss. 2000. Lymphocytes with a complex: adapter proteins in antigen receptor signaling. Immunol. Today 21:584-591.

39. Veillette, A., M. A. Bookman, E. M. Horak, and J. B. Bolen. 1988. The CD4 and CD8 T cell surface antigens are associated with the internal membrane tyrosine-protein kinase p56 $6^{\text {lck }}$. Cell 55:301-308.

40. Wang, B., S. Lemay, S. Tsai, and A. Veillette. 2001. SH2 domain-mediated interaction of inhibitory protein tyrosine kinase Csk with protein tyrosine phosphatase-HSCF. Mol. Cell. Biol. 21:1077-1088.

41. Wange, R. L., and L. E. Samelson. 1996. Complex complexes: signaling at the TCR. Immunity 5:197-205.

42. Weiss, A., and D. R. Littman. 1994. Signal transduction by lymphocyte antigen receptors. Cell 76:263-274.

43. Wienands, J., J. Schweikert, B. Wollscheid, H. Jumaa, P. J. Nielsen, and M. Reth. 1998. SLP-65: a new signaling component in B lymphocytes which requires expression of the antigen receptor for phosphorylation. J. Exp. Med. 188:791-795.

44. Yablonski, D., M. R. Kuhne, T. Kadlecek, and A. Weiss. 1998. Uncoupling of nonreceptor tyrosine kinases from PLC-gammal in an SLP-76-deficient T cell. Science 281:413-416. 